\title{
Redesigning Human Body Systems: Effective Pedagogical Strategy for Promoting Active Learning and STEM Education
}

\author{
Abour H. Cherif, ${ }^{1}$ Dianne M. Jedlicka, ${ }^{2,3}$ Tracey E. Colyer, ${ }^{4}$ \\ Farahnaz Movahedzadeh, ${ }^{5}$ and William B. Phillips ${ }^{6}$ \\ ${ }^{1}$ Math \& Science, College of Liberal Arts \& Sciences, DeVry University, 3005 Highland Parkway, Downers Grove, \\ IL 60515-5799, USA \\ ${ }^{2}$ Anatomy \& Physiology, Columbia College Chicago, 24253 South 80th Avenue, Frankfort, IL 60423, USA \\ ${ }^{3}$ The School of the Art Institute of Chicago, 37 South Wabash Avenue, Chicago, IL 60603, USA \\ ${ }^{4}$ College of Health Sciences, DeVry University, University Academic Affairs, 3005 Highland Parkway, Downers Grove, \\ IL 60515, USA \\ ${ }^{5}$ Department of Biological Sciences, Harold Washington College, 30 East Lake St., Chicago, IL 60601, USA \\ ${ }^{6}$ College of Engineering \& Information Sciences, DeVry University, 2149 W. Dunlap Ave., Phoenix, AZ 85021-2995, USA
}

Correspondence should be addressed to Abour H. Cherif, acherif@devry.edu

Received 6 March 2012; Accepted 22 May 2012

Academic Editor: Gwo-Jen Hwang

Copyright () 2012 Abour H. Cherif et al. This is an open access article distributed under the Creative Commons Attribution License, which permits unrestricted use, distribution, and reproduction in any medium, provided the original work is properly cited.

\begin{abstract}
The human body is a remarkable biological machine maintained by interdependent body systems and organized biochemical reactions. Evolution has worked on humans for hundreds of thousands of years, yet the current pace of technological and social change have radically affected our life style and have exposed possible human frailties. This raises the question of whether or not nature's work could be improved upon. We provide two-sided perspectives as a rationale for the need for the redesign of the human body. Then, we describe pedagogical strategy through which students study morphological and anatomical structures and the physiological functions of the human body systems and their respective organs and parts. The students select their own favorite system or organ to redesign in order to optimize the efficiency of the anatomical structural, physiological function, and/or the aesthetic and functional morphology; a redesign that might lead to, for example, lowering risk of diabetes, heart attack, and/or stroke. Through group work and interaction (student groups compete for a prestigious "in-house" patent award), students actively engage in the learning process in order to understand the role of design in the efficiency and functionality and vulnerability to disease of the human body system.
\end{abstract}

\section{Introduction}

To keep us alive and living, the human body performs millions of complex functions throughout our lifetime. For example, in just 60 seconds, the human body takes 15 breaths, its heart beats 70 times, its tear ducts moisten the eyes 25 times, its brain conducts six million chemical reactions, its bone marrow produces 180 million blood cells, its skin sheds 10,000 particles of skin, and about 300 million of its cells die and/or are replaced [1, 2]. Furthermore, the human body manages to "extract the complex resources needed to survive, despite sharply varying conditions, while at the same time, filtering out a multiplicity of toxins" [3, ๆ 5$]$.

But as Nesse and Williams [5] inquired:

Why, in a body of such exquisite design, are there a thousand flaws and frailties that make us vulnerable to disease? If evolution by natural selection can shape sophisticated mechanisms such as the eye, heart, and brain, why hasn't it shaped ways to prevent nearsightedness, heart attacks, and Alzheimer's disease? If our immune system can recognize and attack a million foreign 
proteins, why do we still get pneumonia? If a coil of DNA can reliably encode plans for an adult organism with ten trillion specialized cells, each in its proper place, why can't we grow a replacement for a damaged finger? If we can live a hundred years, why not two hundred? (p. 3)

Richard Dawkins [4] argues in his well-read book, the greatest show on earth, that animals appear to be elegantly designed, like following an engineer's blueprint. But when an animal is opened up on a dissecting table, it looks more like disorder than architectural design. As an instructive educational exercise, Dawkins proposes a redesign of the arteries leaving the heart: "I imagine the result would be something like the exhaust manifold of a car. ..instead of the haphazard mess that we actually see when we open a real chest" (p. 370-371).

Since much of what we think of as human capacity or intelligence derives from the way the body is constructed more than to the big size of our brains [10], in this pedagogical learning strategy students explore the human body by studying the morphological and anatomical structures, as well as the physiological functions of the human body systems and their organs and parts. They then select their own "favorite" body system, organ, and/or a part of the system to re-design in order to optimize the efficiency of the anatomical structure, physiological functions, and/or the aesthetic and functional morphology. Through group work and interaction, students actively engage in the learning process to (1) learn about the human body from the cellular level, to organ level, to whole system level, (2) understand the role of design in the efficiency and functionality of the human body system, (3) grasp and retain the new information, and (4) apply what has been learned in different situations.

\section{The Human Body}

The human body is a remarkable biological machine that is supported and maintained by well-structured and interdependent body systems and their unique organs, all contributing in different ways to the biological, physical, mental, and emotional health of a human being. It has about a hundred trillion cells, 60 miles of blood vessels, a 3pound brain with 50 to 100 billion nerve cells and amazing thinking capacity, and 2.5 billion heart beats in a life time of 75 years, to name a few of its unique characteristics [2]. However, while thousands of years of evolution have adapted the human body to life on Earth, questions have been raised regarding whether or not the human body could be improved upon to meet, for example, the new challenges of the consequences of our current environment and lifestyles [11]. It is a fact that the human body is a marvel of complexity not only as a whole, but also at other levels of organization including body systems, organs, tissues, and cells. It is also a fact that the human body is "artistically beautiful and worthy of all the wonder and amazement it invokes" [12]. But as John Long [10] has indicated in his recent book, Darwin's Devices, evolution does not always make for better design.
For example, from an engineer's perspective, "it is a complex network of bones, muscles, tendons, valves and joints that are directly analogous to the fallible pulleys, pumps, levers and hinges in machines" [12]. Furthermore, it is also not perfectly efficient when it comes to function and energy saving mechanisms due to the internal designs of few parts, lack of functional purposes in some of its parts, and/or unsuitable locations of a number of its parts or redundancy of parts. For example, it is known that nearness to fuel supply is a fundamental principle in efficient industrial design, but yet, many important organs within the human body are located far away from the main source of fuel energy such as in the case of brain and the heart [13]. Another example is that if the resources (e.g., calcium) for building our teeth go to building fewer teeth, say 21 instead of 32, people might have less cavity problems and decayed teeth, due to infection caused by Streptococcus mutant bacterium [14]. The rest of the calcium could be used to support bones and reduce the bone fractures which are a serious problem for many older people. In addition, and as it is understood now, many human body parts have a limited power of regeneration, meaning they have a limited capability to replicate and/or repair themselves through cell division.

Throughout history humans have been praising the human body as nature's masterpiece and also suggesting a few improvements for various reasons and challenges. For example, more than 45 years ago, Lester David [13] surveyed a group of scientists, engineers, designers, and artists to see what they would suggest to improve the human body. He published his study in an article titled "Science Redesigns the Human Body" in 1956 in the Modern Mechanix Illustrated Journal. Citing George M. Rowland, Jr., one of the former presidents of Burdick-Rowland Associates, a nationally prominent firm of industrial designers at that time, David [13] wrote that

"From a designer's point of view, I see no reason
for a disjointed spinal column. Why not encase
the spine in a tube of semi-flexible cartilage?
Thus man's spine would be a solid column, with
a greatly increased load-carrying capacity. In
addition, the vital nerves in the spine would be
more fully protected against injury. Man would
not be able to twist and turn as he does now but the
semi-flexibility of the cylinder would allow enough
bending for every ordinary purpose." [13, p. 53]

Mr. Rowland has also asked, "Couldn't the brain be situated in the chest cavity, near the heart instead in the head? There is another factor-if the brain was in the chest, it would be far less vulnerable to injury" [13, p. 53]. While this is an interesting idea, this is probably too far from our sensory organs to "work."

The re-design of the human body was also the subject of Ray Kurzweil's talk at the 2003 Time magazine's “The Future of Life" conference. In that talk and in an article with the same title, he discussed his vision of the Human Body Version 2.0. He explained that our bodies evolved in a very different era, under different environmental conditions. For example, 
Our digestive processes in particular are optimized for a situation that is dramatically dissimilar to the one we find ourselves in. For most of our biological heritage, there was a high likelihood that the next foraging or hunting season (and for a brief, relatively recent period, the next planting season) might be catastrophically lean. So it made sense for our bodies to hold on to every possible calorie. Today, this biological strategy is extremely counterproductive. Our outdated metabolic programming underlies our contemporary epidemic of obesity and fuels pathological processes of degenerative disease such as coronary artery disease, and type II diabetes... As we're learning the principles of operation of the human body and the brain, we will soon be in a position to design vastly superior systems that will be more enjoyable, last longer, and perform better, without susceptibility to breakdown, disease, and aging. [3, Sections 6 and 9]

The human body was also the topic of a number of radio and television shows and programs such as the Science Channel, the National Geographic Channel, and the Discovery Channel, to name a few. For example, in 2008, the Science Channel reported the "top 10 useless body parts" by asking can there really be a useless organ? It even offered its viewers a survey to examine their own knowledge by asking them to name the ten most useless body parts. The Science Channel provided the following list of useless body parts: male nipples, appendix, wisdom teeth, arrector pili muscles, coccyx, tonsils, adenoids, sinuses, body hair, and Plica semilunaris. These in fact are evolutionary leftovers that are seen in many living species as signs of earlier lifestyles including physical features, internal processes, and aspects of behavior [15].

While the Science Channel may declare certain organs to be useless, it is important to note that "useless" does not necessarily mean the same thing as a vestige of evolution. A vestige is a trace of something that existed generations ago. Something can be of use and still a vestige, as long as the use is greatly diminished. For example, nipples on males are not a vestige since they did not appear on ancestors which had functional male nipples. On the other hand, human body hair, which is a vestige, is not useless because it is known to aid in the detection of ectoparasites. Thus, students must be made aware of where their information is coming from. They should know the difference between primary (original) and secondary sources of information, and that the Science Channel most likely provides secondary information through its programs.

But still this raises questions such as why are they still there if they do not have, as some believe, any more essential functions for the human body? Can we still survive without them being physically present as part of the human body? Since some evolutionary processes are slow and take time, are these parts already on their way out, and we just cannot recognize it? Why has the evolutionary processes not eliminated them by now or physiologically incorporated them to benefit other parts of the human body? or, perhaps because we do not yet know their essential function, we should assume that they do not have one? (Although this assumption would be very uncharacteristic of scientific thinking.)

Redesigning the human body was also the subject of the BBC Radio 4 FM science program which was broadcast between January and July 2006. In eight audio episodes, Len Fisher wondered how the body would work if we had a go at remaking ourselves (see Appendix A). Len Fisher wondered about almost everything in and on the human body including the skin we are in and the guts we have. Fisher asked whether or not science can come up with anything better, such as a spare pair of arms, eyes in the back of our head, or superhearing, seeing, and touch. But how would the addition of "spare body parts" impact other organs and body systems, such as the brain?

Humans have been fascinated with the human body for many years and have pondered over the many ways it could be enhanced and redesigned. After all, as Nesse and Williams [5] argue in their book, why we get sick, in a body of such exquisite design, there are still a thousand flaws and frailties that make us vulnerable to disease and prevent us from easily living more than a hundred years. This leads us to ask the following question: if you could redesign the human body, what is the one change you would make? This is what makes "redesigning the human body" a worthwhile learning activity. It challenges students to answer a question that is both personal and relevant, allowing students to make connections between the subject matter and their own experiences, helping students to gain a deeper understanding of the human body. By making relevant connections, comparing varying perspectives, examining causality, and raising challenging questions, students are motivated to engage in the learning process. As Boyles and Contadino [16] argue, "an academic struggle begins when students do not have the hooks with which to connect the information given with their own experiences and strengths" (p. 35). However, in "redesigning the human body," all students have the requisite prior knowledge of the human body (after all, they all possess a body and have experienced the benefits and challenges that come with them) and are able to connect with the information being learned.

It is also a worthwhile learning activity because it releases students' thoughts and imagination. It allows them to apply what they learn about the human body and come up with well thought out designs and effective solutions to achieve potential optimum efficiency and functionality for their chosen system or organ. By applying their knowledge of the human body in a new situation, they engage in all of McCormack and Yager's [9] learning domains, from knowledge acquisition to application and connection (see Appendix B).

\section{Learning Activity}

The objective of this learning activity is to help students understand the purpose of design, the relationship of design and function, and how altering the design of a given part, 
organ, or body system could affect the efficiency of that particular part as well as the entire system and the whole living body. Biological design plays vital roles in the survival of the living body and the maintenance of homeostasis throughout the life of the individual (and possibly a role in the survival of the species). Furthermore, we want the students to realize that unlike human design, evolution, which is a gradual process of chemical and physical change, "never starts with an entirely blank drawing board, [but works instead] by modifying things that already exist" ([15], p. 10), thus evolution does not always make for better design [10]. This is simply because, as Dawkins [4] argues, evolution is a genetically controlled alteration in the development program of a given living thing.

A second objective is to actively engage students in group work and interaction not only to achieve a higher depth of understanding, but also to retain new information, and to apply what has been learned in a different situation, namely, the redesigning of their chosen human body system or organ. As Houghton [17] has argued, deep learning which promotes understanding and application for life involves linking new ideas to already known concepts and principles. This leads to a solid understanding and retention of learned concepts so that they can be used for problem solving in unfamiliar contexts or evaluating potential solutions to complex problems.

To begin, students are organized into groups and given the project to redesign a body part, organ, or body system with the goal of being awarded a patent for their design. Each team's design is judged by a team of "patent judges" who determine the winning design. Each group is asked to

(i) select one of the 11 human body systems to research and study,

(ii) identify and describe in writing the morphological and anatomical structure and the mechanical and physiological function of the given selected system and its main organs and parts,

The students should

(i) include the description of specific function of the entire system as well as each organ and part within the system,

(ii) identify the relationship within the structure,

(iii) use, complete, and submit Table 1 as a summary factfinding sheet,

Additionally, students are then asked to:

(i) identify the part, organ, or whole body system to study and re-design,

(ii) develop a convincing argument that their re-design is better and more efficient for achieving its main intended functional purpose. (Students use Tables 2 and 4 to help them organize their information of comparing and constructing the original design and the re-design of the selected body system, organ, and or part.)
After the initial presentation by the instructor, the students are given time (from 2-3 weeks) to work together and collect additional information necessary to develop a plan to redesign their selected part, organ, or body system. Subsequently, they implement their plan by creating detailed drawings and a written description of their re-design. The idea behind the redesign is to show how the redesign might lead to more desirable results. The members of each group must successfully argue to convince the class that their redesigned body system, organ, or part leads to a big improvement in the efficiency of that organ or part, and thus worthy of achieving a patent. (Patents are very prestigious and everyone wants a patent to make a name for themselves or their company.)

By engaging in research, studying the human body systems in detail, redesigning a given system, organ, or part and developing and presenting an informative and scientifically convincing argument for the efficiency of the redesign, the students learn to organize information, examine causality, compare varying perspectives, make choices, and improve social skills. Most of all, students reinforce their understanding of the composition and function of body systems and their organs and the interrelationships they play in the survival and health of the living individual. The finalized project is then presented to the class and to "patent judges." Judges may be the class members or the instructor or visiting volunteer instructors.

By learning the reasons for the judges' choice, students gain insight into other individuals' thought processes. While the students may have effectively presented the importance of their re-design, the judges may have found another group's re-design more important due to the level of significantly enhanced functionality made by the re-design. After the judging, the class instructor needs to reinforce the "why" behind all the re-designs. The class instructor reinforces the idea of homeostasis and organ-system interrelationships, the need for continuous improvement, and the long-term biological mechanisms of how organisms respond to changes in their environment. Teachers should also emphasize the role of evolution and natural selection in the development of species.

\section{Procedures}

This learning activity can last two hours or two weeks, including preparation and presentation time. Both time frames work well.

\subsection{Before Presentations}

(1) Form an evaluation committee which consists of the instructor of the class, another instructor from the school and one academically respected student from the same class (or have a "class vote/peer review" at the end of the presentations). The evaluation committee uses Table 5 to help them make its decision on which of the presentations should receive the very much coveted "Re-design Patent Award." 


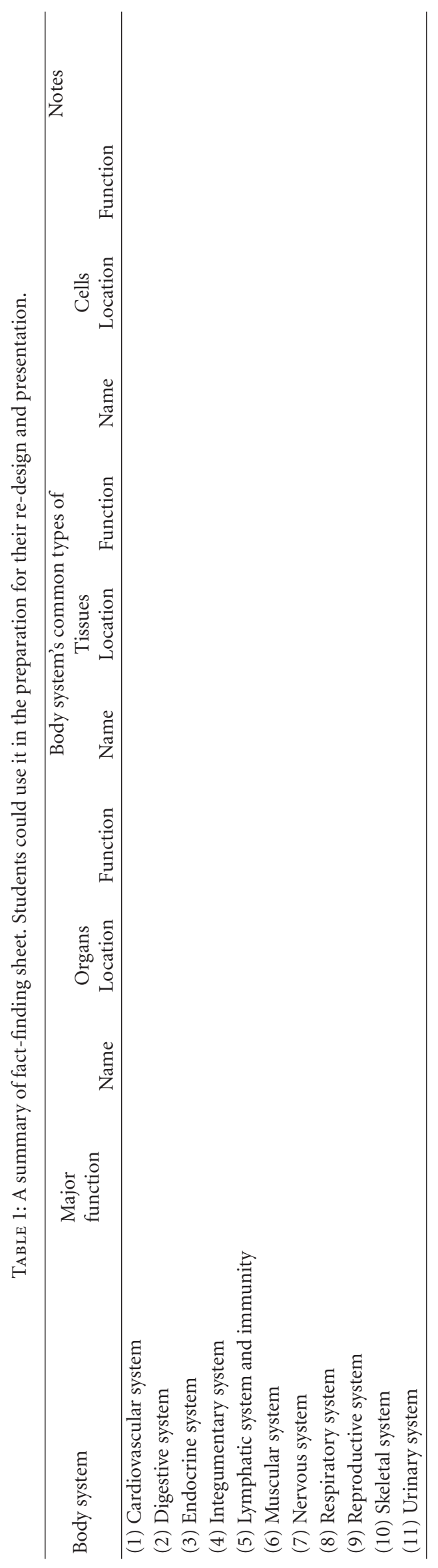


TABLE 2: Comparing and constructing the original design and the redesign of selected body system, organ, and/or part.

\begin{tabular}{lccc}
\hline $\begin{array}{l}\text { Targeted area of } \\
\text { redesign }\end{array}$ & $\begin{array}{c}\text { Description of the } \\
\text { original design }\end{array}$ & $\begin{array}{c}\text { Description of the } \\
\text { re-design }\end{array}$ & $\begin{array}{c}\text { Predicted } \\
\text { outcomes of the } \\
\text { re-design }\end{array}$ \\
\hline
\end{tabular}

(2) Ask students to provide their own perspective on the status of the human body's design by completing Table 3. Give the students 10-15 minutes to complete this assignment. Collect their answers, and keep them for a future assignment or an additional discussion after the awards are presented. Then, engage the students in open discussion about their perspectives.

(3) Ask each group of 3 students to select one of the 11 human body systems to research and study. Allow the groups to inform each other of their selections, as well as to exchange selections and choices if they wish. This will make the groups more committed to their selections $[18,19]$.

(4) Give the students 2-3 weeks (time can be shortened or lengthened) to prepare for their class presentation, and inform the groups to do the following.

(a) Research and prepare a well-informed written paper providing informative and convincing arguments that their re-designed part, organ, or body system is important and more efficient for its intended purpose than the original design. Since evolution "never starts with an entirely blank drawing board, but works by modifying things that already exists" ([15], p. 10), students must use the existing design as a basis for every proposed re-design.

(b) Be well prepared to engage in a meaningful discussion and provide sound evidence to convince their classmates that their re-design is really needed and thus deserves one of the Redesigned Patent Awards.

(c) Have a well-researched hand-out to be distributed to the classmates before the presentation, as well as an illustrated poster, poem, song, cartoon, and so forth that can help convey the group's rationale for and support its re-design of the selected part, organ, or body system.

(d) Integrate the use of technology in their presentation, such as the use of PowerPoint, animations, interactive activities, as well as songs/poems, among others, to present their redesign and the rationale beyond it.

(5) To ensure that all students start their research from the same level of knowledge and information, students are advised to start their research by reading at least 5 of the following articles:

(a) Anonymous [20].

(b) Carmena [21],

(c) Daniels et al. [1],

(d) David [13],

(e) Fisher [22],

(f) Kurzweil [3, 23],

(g) Lauarace [11],

(h) Muneoka, et al. [24],

(i) Stock [25],

(j) Human Body. National Geographic Video, http://science.nationalgeographic.com/science/ health-and-human-body/human-body/

(6) At class meetings, make sure that students are working on their assignments. For example, give 1015 minutes to the members of each group at the end of the class meeting to sit together and reflect on how they are doing on the preparations for their re-design, written paper, poster making, and other additional aids. The teacher may want to discuss how to prepare a meaningful argument to convince their classmates that their re-design of the selected part, organ, or body system is important, efficient and needed in the human body and thus deserves to receive the Re-design Patent Award. Students can use their completed Tables 1, 2, and 3 to initiate useful discussions in the class.

\subsection{During the Presentation}

(1) The members of each group take turns presenting their re-designed selected part, organ, or body system 
TABLE 3: Students' perspectives on the status of the human body's design.

\begin{tabular}{lllll}
\hline The status of the human body design & $\begin{array}{l}\text { Strongly } \\
\text { disagree }\end{array}$ & Disagree & $\begin{array}{c}\text { Neutral } \\
\text { Agree }\end{array}$ & $\begin{array}{c}\text { Strongly } \\
\text { agree }\end{array}$ \\
\hline
\end{tabular}

(1) Human body is perfectly designed; No need for improvement.

(2) Human body is well designed; but can benefit from a few

improvements.

(3) Human body is functional with ok design, and can benefit from a few re-designs for improvement.

(4) Human is functional, but not perfectly designed, and can benefit from the re-designed of many of its parts.

(5) Human body needs total re-design to optimize its

efficiency and functionality.

(6) Wonderfully design doesn't necessary mean also wonderfully develop.

(7) Wonderfully develop doesn't necessary mean also wonderfully made.

(6) and (7) are modified from Dawkins [4].

TABLE 4: Identified targeted areas for enhancement within the selected areas in given human body systems and or its organs.

Targeted area of enhancement

(1) Physiological function

(2) Neurological and communication function

(3) Structural and supportive function

(4) Morphological and aesthetic function

(5) Anatomical function
Underline proposed enhancement

Reasons

Mechanism

Predicted outcomes to the class. The evaluation committee/judge questions each group. The students in the class can ask up to three questions after a group completes its presentation. In addition, the members of each group take notice of all the questions that are asked.

(2) After all groups finish presenting their cases, the members of the evaluation committee (judges) can ask more questions to all the groups. The students can also ask questions which the members of the evaluation committee must consider in their final judgment and decision for awarding the Re-design Patent Award to a given group.

(3) The members of the evaluation committee wait until the next class meeting before sharing their final decision with the groups. During this time, and if there is room in the school, the posters, illustrations, and poems, and so forth) can be made available for all the students to view.

\subsection{After the Presentation}

(1) In making their final decision, the members of the evaluation committee take into consideration the following. (a) The academic quality and integrity of the written paper, the oral presentation, the poster illustration, and/or any additional aids used by the students to help them convey their message, and demonstrate the importance of their redesign.

(b) The use of the appropriate scientific concepts and principles in the re-designing of the selected part, and the accurate interpretation of scientific concepts, principles, and terminology. In addition, the use of the original design as a basis for the re-design (Tables 2 and 4).

(c) The delivery of the presentations, the articulation of their arguments, the demonstration of the interrelationship between design, structure, and function, and the individual's personal involvement and engagement during the presentation and class discussion.

(d) The type and quality of questions being asked during the process. In addition, the quality of the answers the groups provided to questions directed to them. (Teachers and instructors can see Cherif, et al. [19] for useful tools and techniques that can be used to monitor the level of cognitive involvement of the members of a 
TABLE 5: Re-design patent awards and the reason behind they being awarded.

\begin{tabular}{l}
\hline Patent award $\quad$ Awarded for \\
\hline (1) Platinum \\
(2) Gold \\
(3) Silver \\
(4) Bronze \\
(5) Honorary mentioned
\end{tabular}

given group during the activity as well as to record the type of questions being asked by the members of a group, the relevancy of the questions to the subject matter and to the point being debated, and to record the number of questions being asked by the members of one group to the other groups.)

(2) Each group is given 2-3 minutes to address the committee one more time before the members of the evaluation committee read the final decision. In this short final remark, the groups must have a written statement that can be read to support their case of re-design and request for the Re-design Patent Award, based on a significant enhancement made in their redesign as well as academic accuracy in their proposal.

(3) After all the groups present their final remarks, a representative of the evaluation committee reads and defends the committee's final decision. The members of the evaluation committee provide each group a copy of Table 5 which represents the committee's final decision.

(4) The class Instructor must reinforce the concepts of design, patent (copyright), interrelationships of design, structure, and function, and the role homeostasis plays within a given body system in order to work effectively. (If, or when, the vermiform appendix is brought up the instructor can lead a very interesting discussion.) In an evolutionary sense, the instructor can comment that it once was extremely important and is now vestigial, but still it is not useless simply because something could be of use and still a vestige, as long as the use is greatly diminished.

\section{Discussion Questions}

The following questions can be used throughout this learning activity to generate discussion and engage students in critical thinking. Additional important discussion questions for promoting the development of deep thought and reflection among students on what they learned and understood from the activity can be seen in Appendix C.

(1) Discuss the contribution of your selected body system to overall body systems as well as to each individual body system.
(2) Explain how your proposed re-design enhancement helps illuminate common occurrences of a given disorder and or disease.

(3) Which organ (or organs) in an adult human body is able to regenerate naturally, to the extent that a living person can donate part of this organ to someone else, and within several weeks the two parts of this organ will regenerate into functioning, near-normal-sized organs?

(4) Which organs in an adult human body are able to repair themselves after minor trauma?

(5) Why is stem cell research important? What are the differences/similarities between embryonic and somatic stem cells? What is tissue grafting all about? Are these two techniques part of your re-design plan? Why or why not?

(6) If you want your re-design to become reality and to appear generation after generation, at which level do you start your re-design: Molecular (DNA) level, embryonic development level, toddlerhood level, adulthood level? Explain.

(7) Recently, it has been reported that Chinese researchers were able to regenerate skin from deep burns without the use of tissue grafting. What role can stem cell research and technology play in the regeneration of human body tissues, organs, and parts?

(8) Capitalizing on the vast accumulation of this type of knowledge, biologists hope to make limb regeneration as well as other human body parts and/or organs a reality. Conduct library research and then discuss whether regeneration is better than redesign of your selected part, organ, or body system.

(9) It has been known for centuries that simple animals such as worms and starfish can be easily cloned by cutting them in half. However, this method does not work for higher animals because of cell specialization. Conduct library research to find out how scientists overcome this obstacle in cloning higher animals.

(10) While nothing can currently stop the process of aging, when it comes to the human life span, what percent of aging is accounted for by DNA and what percent is accounted for by behavior and lifestyle of a given individual? Explain.

(11) Many researchers of aging prefer to use the term "healthy span" instead of "life span" and "active-life 
expectancy" instead of "life-expectancy." Conduct library research and then explain the meaning of each term and the advantage of using one over the other.

(12) Ask your students to answer the following question

(a) What type of body must you have in order to live to 100 ?

(b) Give them 20 minutes to finish their assignment.

(c) Discuss their answers in the class. Then share with them the following.

The body you want is short and squat, with stooped shoulders, backward-bending knees, pointy ears and hefty muscles. In other words, a gnomish creature that could rate a perfect 10 for mechanics and a total zero for glam. [This type of body might not bring you romance, but] at least, that's the vision of three of the nation's leading longevity researchers, who've come up with a blueprint for a human form that's built to last, if not forever, then certainly long past middle age, when the vagaries of gravity and nature start taking their toll on everything from perfect pecs to microscopic ear hairs. [26, Section 1].

\section{Assessment}

For assessing student's performance and understanding, as well as the effectiveness of these activities, we have been using McCormack and Yager's [9] taxonomy for science education as a framework for students' achievement. Appendix B contains a summary of McCormack and Yager's [9] taxonomy. It also contains some examples of assessment criteria that we have used in this activity. Notice that many assessment questions could fall into more than one domain depending upon how the questions are framed.

6.1. Related Activities to Reinforce and Expand upon the Learning Objectives. Additional activities can be designed and conducted to reinforce the understanding of the desirable learning objectives. Some possible examples include the following.

Homework Assignments (Optional). To reinforce the learning objectives of the activity, ask students to engage in the following homework assignments, either individually or in groups.

Homework Assignment 1. Ask students to answer the following questions (give them a time limit such as 10 minutes or the next class meeting).

(1) Reflect on the final decision made by the members of the evaluation committee. Do you agree with it? Why or why not?

(2) What have you learned from the activity at both academic and personal levels?
(3) If you had to do this all over again, what would you change, discard, or add? Why?

(4) On the Science Channel, a "top 10 useless body parts" was reported. Go to the web address below to read about them and conduct a library search to learn more about body parts such as these. Then complete Table 6. Make sure to critically complete all the columns, especially column 6 which requires you to justify your agreement or disagreement with the findings of the Science Channel on this specific topic. (http://science.discovery.com/top-ten/2008/organs/ organs.html).

Homework Assignment 2. While there is always exception to the rule, animals that die naturally over a period of time can provide significant data on how long they are expected to live. This is called the average life span of a given organism. Conduct research to determine the maximum life span of 12 living organisms. Include in this list humans, lions, monkeys, eagles, turtles, lobsters, and alligators. Then use Table 7 below to answer the following questions.

(1) list the maximum life span of each organism.

(2) identify which of these 12 organisms:

(a) do and which do not suffer the indignities of aging,

(b) keep on growing throughout their lives,

(c) show no obvious loss of function as they get older.

(3) is there a relationship between

(a) the size of the organism and its maximum life span?

(b) the type of the organism and its maximum life span?

(c) the environment in which a given organism lives and its maximum life span?

Homework Assignment 3. A disease is a condition in which the normal state (homeostatic regulations) of an organism is disturbed or impaired. It is usually characterized by specific diagnostic symptoms and signs that resulted from the distribution of the normal function of cells, tissues, organs, and/or systems by pathogenic organisms and thus, the body becomes incapable of performing normal functions. Conduct research to learn more about the human body and diseases and then answer the following questions:

(1) choose an organ system.

(2) list the organs and their common diseases. Then, answer the following questions:

(a) which organs are the most susceptible to disease? Explain.

(b) which organs are the least susceptible to disease? Explain. 
TABLE 6: 10 useless body parts as reported by the science channel.

\begin{tabular}{|c|c|c|c|c|}
\hline $\begin{array}{l}\text { Useless body part as reported by the } \\
\text { science channel }\end{array}$ & $\begin{array}{l}\text { Meaning or } \\
\text { definition }\end{array}$ & $\begin{array}{l}\text { Organ/non- } \\
\text { organ and } \\
\text { why }\end{array}$ & $\begin{array}{l}\text { Organ system it } \\
\text { belongs to }\end{array}$ & $\begin{array}{c}\text { Agree or disagree with } \\
\text { science channel and } \\
\text { why? }\end{array}$ \\
\hline
\end{tabular}

(1) Male nipples

(2) Appendix

(3) Wisdom teeth

(4) Arrector pili

(5) Coccyx

(6) Tonsils

(7) Adenoids

(8) Sinuses

(9) Body hair

(10) Plica semilunaris

(11) Your chosen body part (organ)

The human intestine contains trillions of microbes of at least 1,000 different species. Scientists are interested in learning more about how these organisms affect our lives and health. These types of studies have improved our understanding of the interactions between the normal gut flora and the immune system which led to the identification of the appendix as an apparent safe-house for normal gut bacteria. In a recent article, Bollinger et al. [6] proposed that "the human appendix is well suited as a "safe house" for communal bacteria, providing support for bacteria growth and potentially facilitating reinoculation of the colon in the event that contents of the intestinal tract are purged following exposure to a pathogen.” (p. 826). In additional, more and more recent articles add a much stronger refutation of the appendix as useless. Students are advised to look at, for example, the article written by Im et al. [7] in which the authors argue that the presence of an appendix might have a significant and independent function in helping to protect humans against Clostridium difficile recurrence (CDI) which causes gastrointestinal infection resulting in diarrhea and colitis. Clostridium difficile is a spore-forming anaerobic, and gram-positive bacterium that is raised in the human gut. Furthermore, another interesting study indicated that the cecal appendix may be viewed as a part of the immune system because is vital to life in a "natural" environment, but which is poorly suited to postindustrialized societies [8]. The conclusion is that teachers and instructors must emphasize the fact that something can be of use and still a vestige, as long as the use is greatly diminished.

TABLE 7: The average life spans of selected organisms.

\begin{tabular}{|c|c|c|c|c|}
\hline Example of selected organism & $\begin{array}{c}\text { Average maximum } \\
\text { life-span }\end{array}$ & $\begin{array}{c}\text { Suffer the indignities } \\
\text { of aging }\end{array}$ & $\begin{array}{l}\text { Keep growing } \\
\text { throughout their lives }\end{array}$ & $\begin{array}{c}\text { Showing obvious Loss } \\
\text { of function as they get } \\
\text { older }\end{array}$ \\
\hline
\end{tabular}

\section{Humans}

Eagles

Lions

Monkeys

Turtles

Alligators

Galapagos land tortoises

Sharks

Sturgeons

Lobsters

(c) is there a relationship between the location of an organ in the human body and its susceptibility to a given disease? Explain.

(d) is there a relationship between the organ system into which a given organ belongs and its susceptibility to a given disease? Explain.

(3) list all the selected organs, their common functions, their common type of tissue, and whether or not they belong to more than one organ system.
(4) list all the organ systems, their estimated average weight, the estimated average human body weight, and the ratio of the organ weight to the whole body weight.

Final Remark. In this activity, we have created a learning environment and pedagogical opportunity for students to learn about the human body through redesigning some of its systems, organs, and/or parts with the aim to optimize body systems and efficiency without sacrificing functionality. 
We hope that students develop an understanding that optimization could improve all system parameters in the human body, and also that the biological improvement of the human body through the re-design of some of its part is not only possible, but achievable and unavoidable. Additionally, we hope that we have created a learning activity through which students are challenged to learn new information about the human body, make strong connections with this information, and apply it in a new context, so that true understanding and long-term retention of knowledge is gained.

In their book, Why we get Sick, Nesse and Williams [5] argue that "despite their exquisite design, our bodies have crude flaws; despite our multiple defenses, we have a thousand vulnerabilities; and despite their capabilities for rapid and precise repairs, our bodies inevitably deteriorate and eventually fail" (p. 235). But as Gregory Stock [25] wrote in his article, The Last Human, "Never before have we had the power to manipulate human genetics to alter our biology in meaningful, predictable ways" (Section 4). Over the past hundred years, the field of biology has shifted from description to understanding to manipulation. In one century, "we have moved from observing to understanding to engineering" ([25], Section 24). And through this activity, we hope that we promote both active learning and STEM education among students.

\section{Appendix}

\section{A.}

See Table 8

B.

\section{See Table 9}

\section{Promoting Deep Thought and Reflection}

Toward the end of the semester and after completion of all the activities related to the re-design of the human body, it is worthwhile for teachers and instructors to engage their students in a discussion that promotes the development of deep thought and reflection on what they learned and understood from the activity. The authors of this paper have found that the following questions, which have been suggested by one of the reviewers at the Education Research International, are very useful in achieving this goal. While all of these questions are educationally useful, we suggest that you select those questions that are related to the course you teach and the type of students you have.

(1) Does the human still need to look and act human?

(2) Are changes in I.Q. allowed, and are changes allowed which make the organism look nonhuman?

(3) What about changes which alter tendencies toward aggression, fear, or other types of psychosocialrelated issues?
(4) Should scientists be allowed to make changes without addressing exactly how those changes are made?

(5) Do we allow students to alter aging? If so, do they need to consider the impact on society?

(6) Many people differ on what is a vestige or what is useless and what is not. "Useless" does not necessarily mean the same as a vestige of evolution. Explain the difference between both of them and provide examples of each.

(7) Why do scientists always advise their students to go and investigate the original research rather than going to, for example, Science Channel and popular science news outlets?

(8) There is controversy within the scientific literature regarding whether the appendix in humans has a useful function or is useless. You are a science journalist who is asked to put an end to this controversy by reporting on those who support and those who strongly refute that the appendix is a useless part of the human body.

(9) You are a science journalist who is asked to investigate the phenomena of obesity in human society before and after the industrial revolution. Conduct investigative research to explain the difference in the trend of the increasing or decreasing rate of obesity and their root causes between these two distinct periods of human history.

\section{Alternative Approach to the Learning Activity}

Changing the time frame from a long project taking weeks or multiple class periods to one class period allows for a quicker "turn around" of information but does require some advanced study. Some of us have successfully conducted this activity with each organ system on a weekly basis to help students really understand the relationship between organs within each organ system. Students are given 20 minutes to form an argument and develop a short presentation, that is, supported with a poster, poem, and so forth. Then, each group of students is given 5 minutes to present their organ. This works extremely well for the digestive system's organs (as stated by a number of students in one of the coauthor's class). After all organs have been presented or "argued"/debated over, the class votes based on the presentations/persuasions. There is much to compare and contrast in this learning activity. This can have a lively impact on the class's cohesiveness and can increase the "learning curves" of all students [27, 28]. The active participation "grabs" them. Continued references to a prior presentation/debate brings smiles and recollections to the students. Instructors can then build on that knowledge foundation and move on to the next organ system. Test scores were higher on topics that were covered in this manner as compared to the more traditional PowerPoint lecture topics presented by the instructor. 


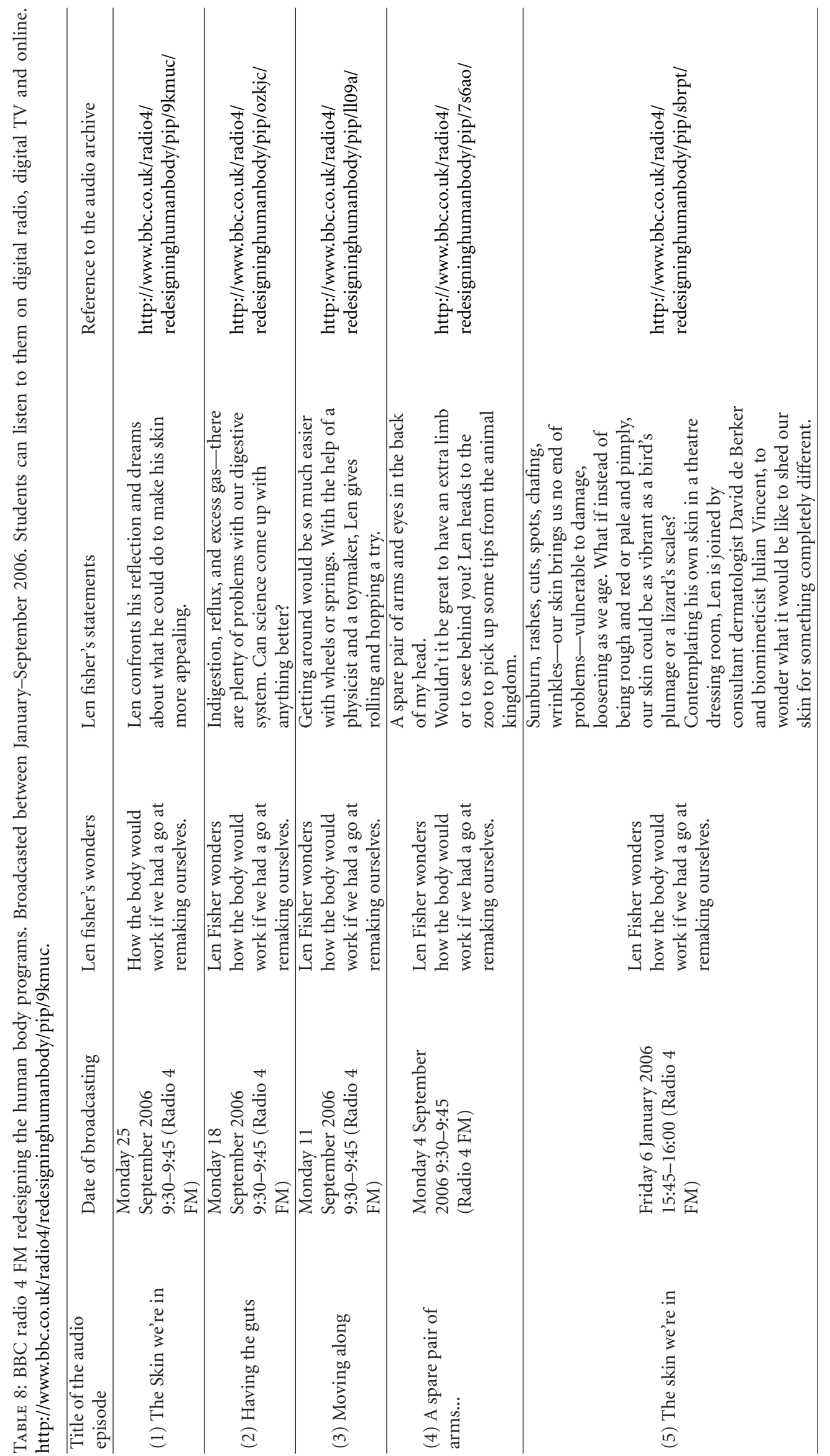




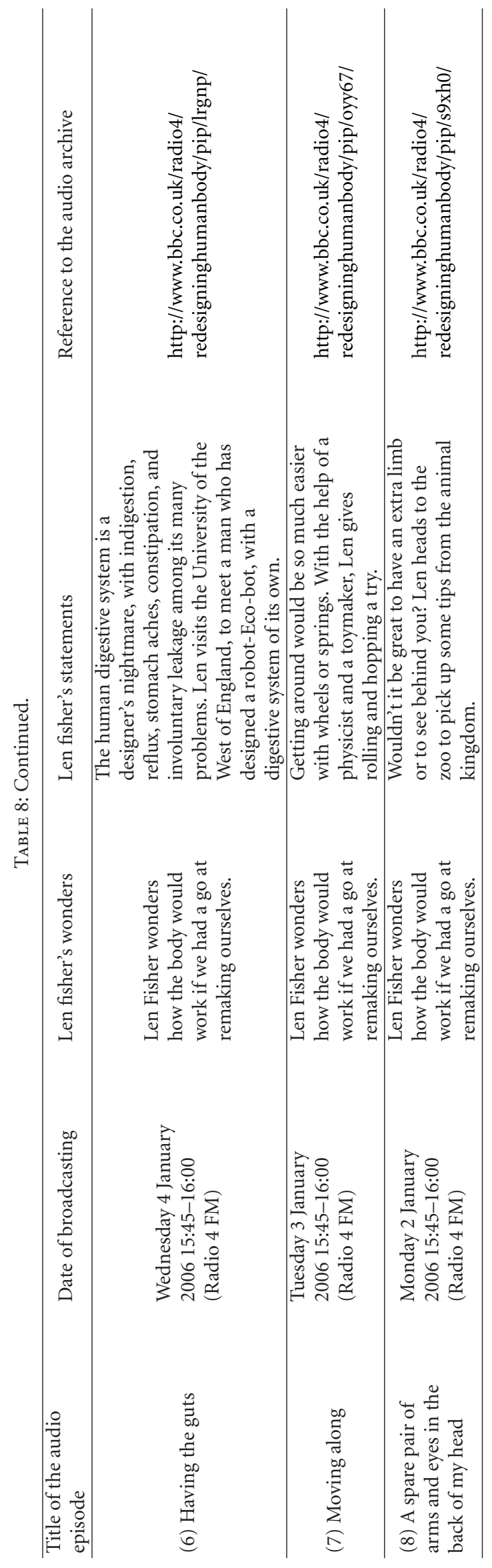




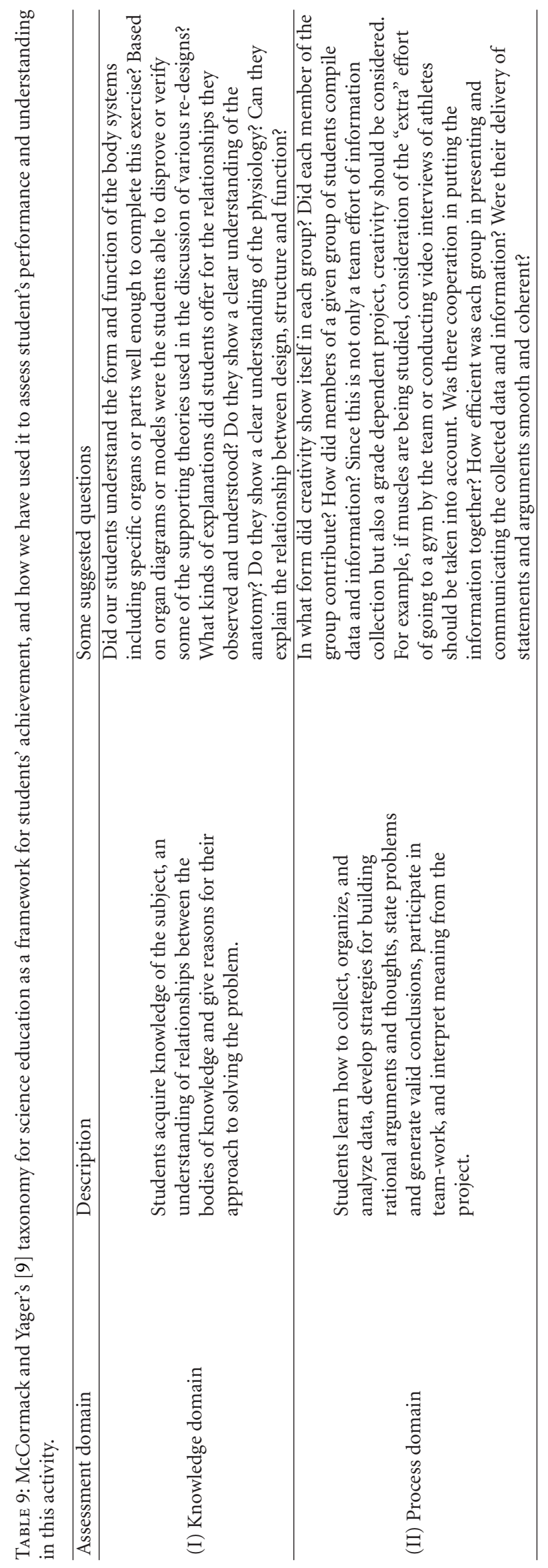




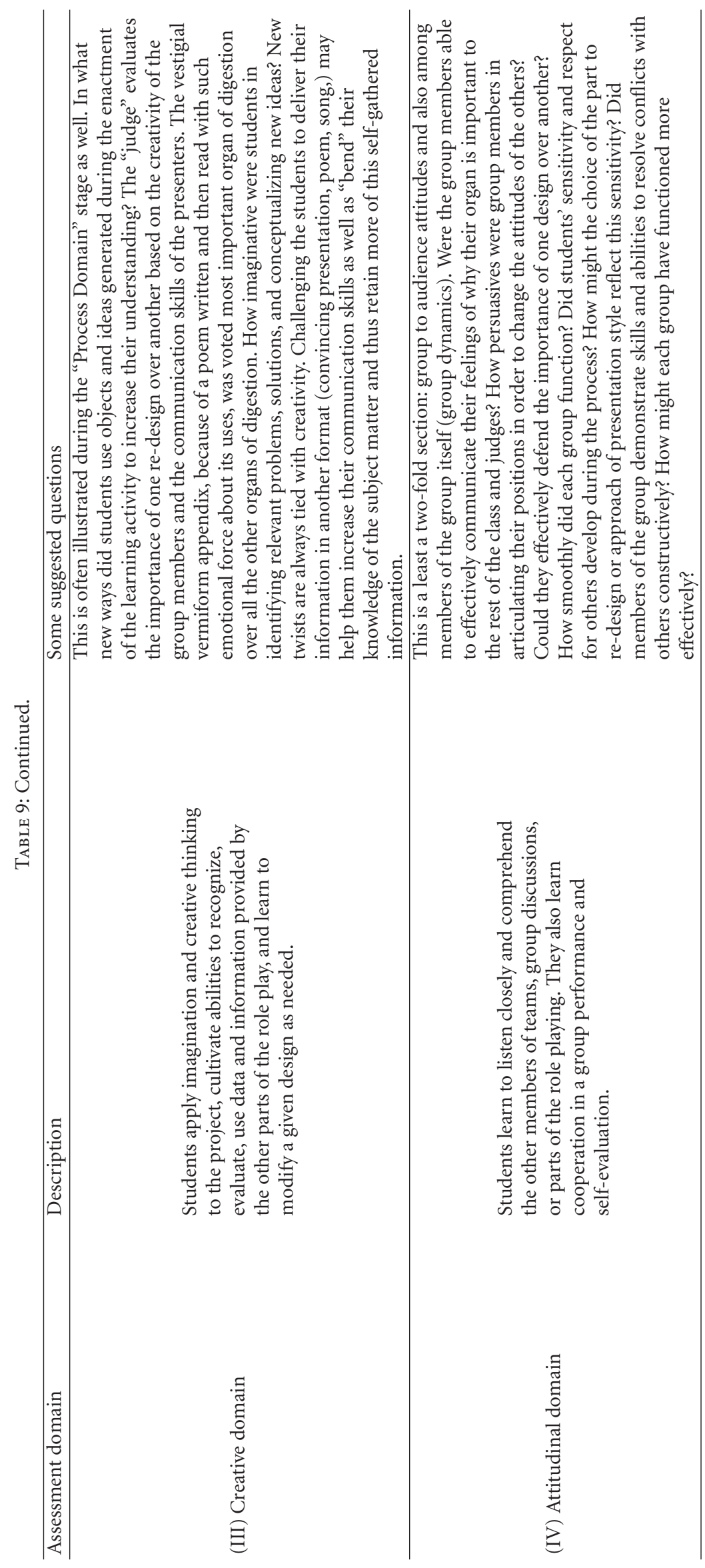




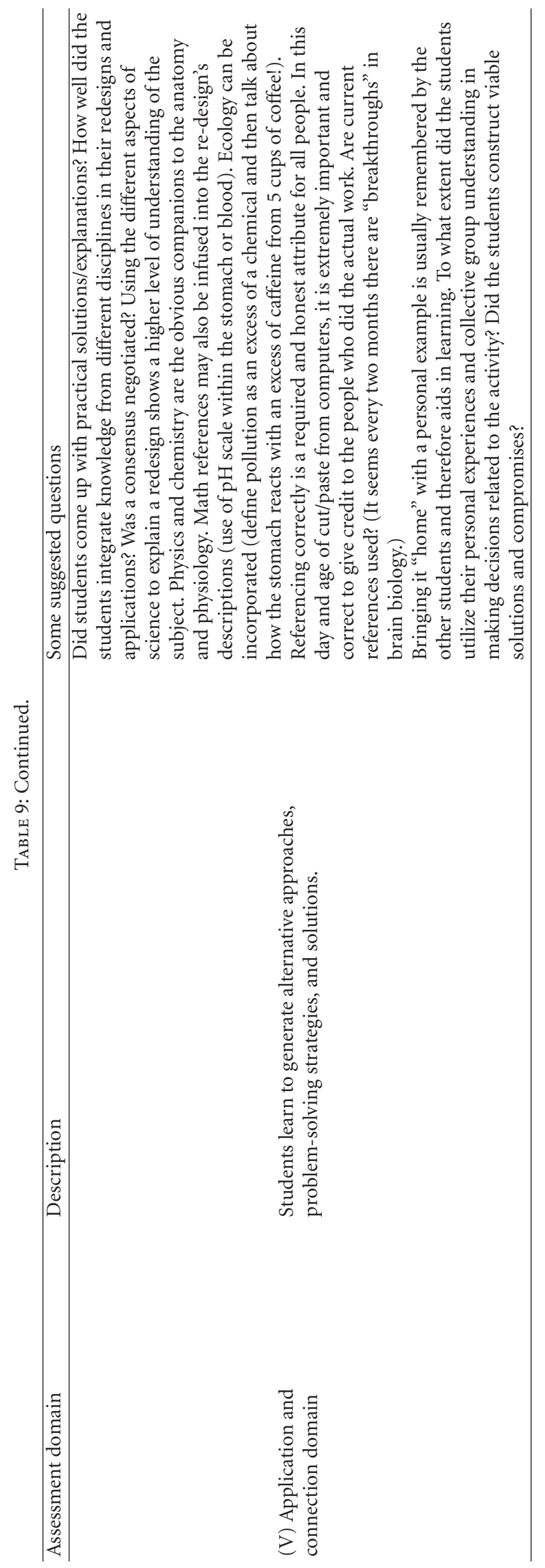




\section{Acknowledgments}

We would like to express our gratitude to the people who reviewed and provided constructive feedback for this manuscript: Dr. Maris Rose, Dr.Mathew Bruder, Dr. GwoJen Hwang, Ms. Erica Solomon.

\section{References}

[1] P. Daniels, L. Stein, T. Gura et al., Body: The Complete Human, National Geographic Society, Washington, DC, USA, 2007.

[2] R. M. Poole, Ed., The Incredible Machine, National Geographic Society, 1994.

[3] R. Kurzweil, Human Body Version 2.0, KurzweilAI.net, Presented at Time Magazine's in "The Future of Life" Conference, February 2003, http://www.kurzweilai.net/human-body-version-20.

[4] R. Dawkins, The Greatest Show on Earth, The Free Press, New York, NY, USA, 2009.

[5] R. Nesse and G. Williams, Why We Get Sick: The New Science of Darwinian Medicine, Vintage Books, New York, NY, USA, 1994.

[6] R. Randal Bollinger, A. S. Barbas, E. L. Bush, S. S. Lin, and W. Parker, "Biofilms in the large bowel suggest an apparent function of the human vermiform appendix," Journal of Theoretical Biology, vol. 249, no. 4, pp. 826-831, 2007.

[7] G. Y. Im, R. J. Modayil, C. T. Lin et al., "The appendix may protect against Clostridium difficile recurrence," Clinical Gastroenterology and Hepatology, vol. 9, no. 12, pp. 1072-1077, 2011.

[8] M. Laurin, M. L. Everett, and W. Parker, "The cecal appendix: one more immune component with a function disturbed by post-industrial culture," The Anatomical Record, vol. 294, no. 4, pp. 567-579, 2011.

[9] A. J. MacCormack and R. E. Yager, "Toward a taxonomy for science education," B. C. Catalyst Journal, vol. 33, no. 1, pp. 16-17, 1989.

[10] J. Long, Darwin's Devices: What Evolving Robots Can Teach Us about the History of Life and the Future of Technology, Basic Books, New York, NY, USA, 2012.

[11] J. Laurence, "Human being, mark II: how would we redesign ourselves?" The Independent (Health News Section), 2006.

[12] J. S. Olshansky, B. A. Carnes, and R. N. Butler, "If humans were built to last," Scientific American, vol. 284, no. 3, pp. 5055, 2001.

[13] L. David, "Science redesigns the human body," Modern Mechanix, pp. 52-55, 1956.

[14] K. Muratsu, Teeth Are Our Organs, KOS, Fukuorka, Japan, 2011.

[15] D. Burnie, Evolution, Dorling Kindersley, New York, NY, USA, 2002.

[16] N. S. Boyles and D. Contadino, The Learning Differences Sourcebook, McGraw-Hill, New York, NY, USA, 1998.

[17] W. Houghton, Engineering Subject Centre Guide: Learning and Teaching Theory for Engineering Academics, Higher Education Academy Engineering Subject Centre, Loughborough University, Loughborough, UK, 2004, http://www.engsc .ac.uk/er/theory/learning.asp.

[18] A. Cherif, F. Movahedzadeh, L. Michel, A. Hill, and D. Jedlicka, "Environmental release of genetically engineered mosquitoes: is it safe? A role playing activity for STEM education," Science Education and Civic Engagement, vol. 3, no. 1, pp. 15-25, 2011.
[19] A. Cherif, L. Michel, F. Movahedzadeh, R. Aron, G. Adams, and S. Jenkins, "Defending the lowly prokaryotes: new challenges for biogaia learning activity," The American Biology Teacher, vol. 71, no. 6, pp. 346-353, 2009.

[20] “Grow a limb," Science Illustrated, pp. 82-85, March-April 2008.

[21] J. M. Carmena, "Becoming bionic," IEEE Spectrum, vol. 49, no. 3, pp. 24-29, 2012.

[22] L. Fisher, BBC—Radio 4, Redesigning the Human Body, Programs Broadcasted between January-September 2006, http:// www.bbc.co.uk/radio4/redesigninghumanbody/pip/9kmuc.

[23] R. Kurzweil, "The human body version 2.0," in The Scientific Conquest of Death, pp. 93-122, Immortality Institute, 2004.

[24] K. Muneoka, M. Han, and D. M. Gardiner, "Regrowing human limbs," Scientific American, vol. 298, no. 4, pp. 56-63, 2008.

[25] G. Stock, Redesigning Humans: Our Inevitable Genetic Future, KurzweilAI.net, 2002, http://thephora.net/forum/showthread .php?t=5541.

[26] M. Ingrassia, "If scientists could redesign the human body, here are some of the changes they'd make," Daily News, 2001, http://articles.nydailynews.com/2001-06-04/entertainment/18 169385_1_human-body-international-longevity-center-aging.

[27] A. Cherif, D. Jedlicka, A. Al-Arabi, R. Aron, and S. Verma, "Effective understanding of the human body organs: a roleplaying activity for deep learning," The American Biology Teacher, vol. 72, no. 7, pp. 447-450, 2010.

[28] A. Cherif, L. Michel, F. Movahedzadeh, J. Siuda, G. Adams, and R. Aron, "Reinforcing the importance of hypotheses in the scientific method of inquiry: a learning activity using the 2006 Spinach contamination event," Washington Science Teachers' Journal, vol. 51, no. 1, pp. 34-40, 2010, http://washsta.com/download/wstamembers.htm. 


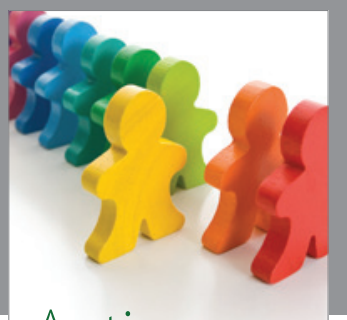

Autism

Research and Treatment
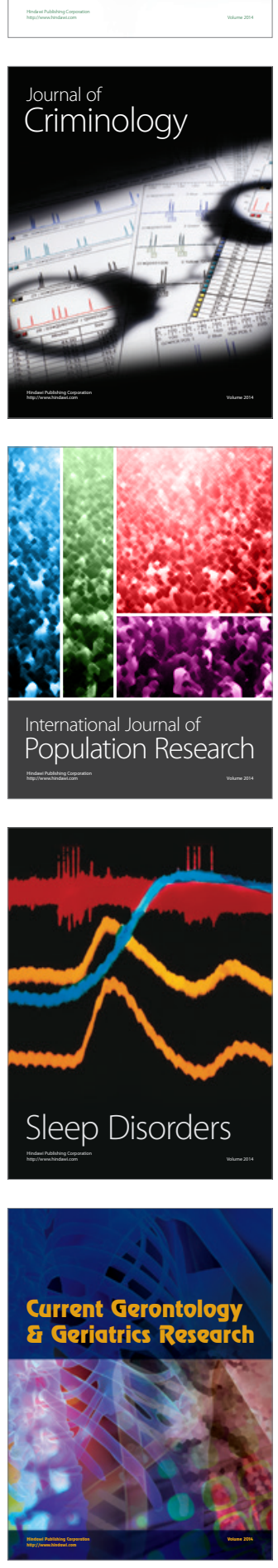
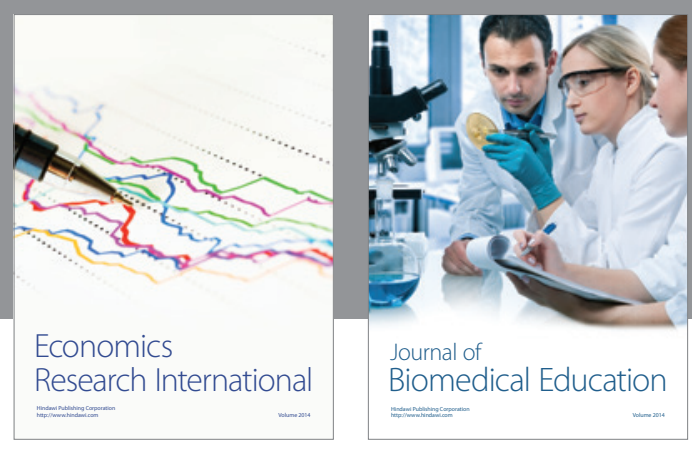

Journal of

Biomedical Education

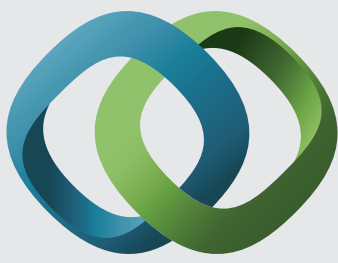

\section{Hindawi}

Submit your manuscripts at

http://www.hindawi.com
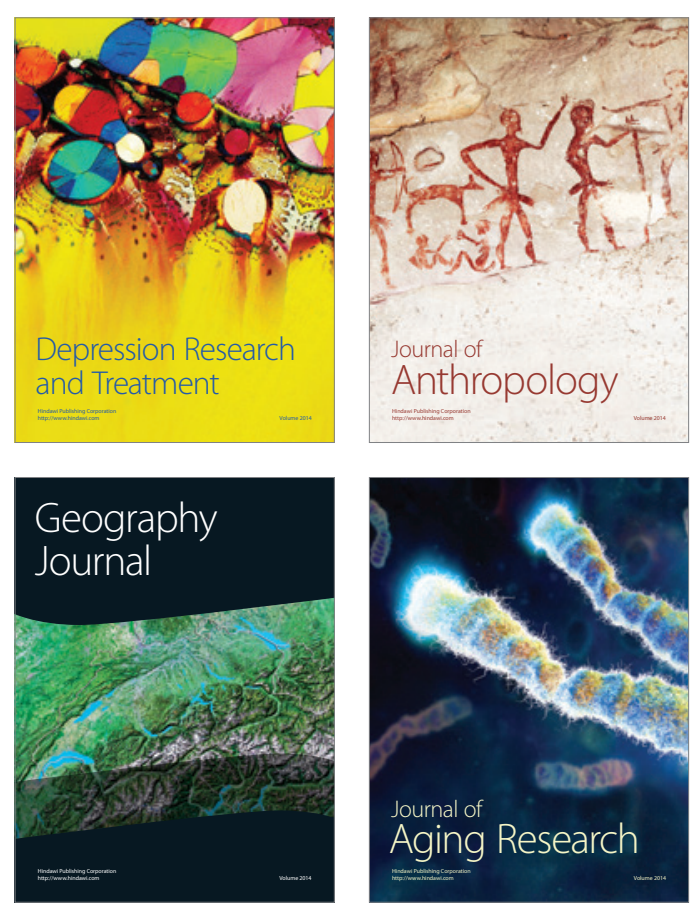

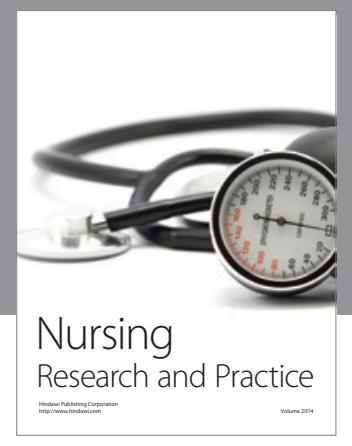

Nursing

Research and Practice

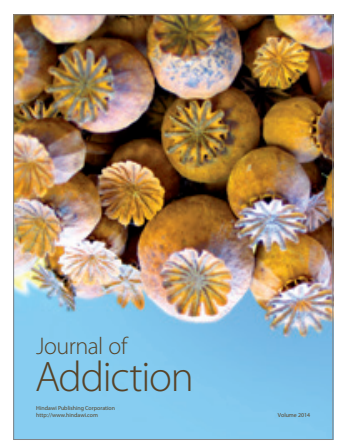

Child Development

Research

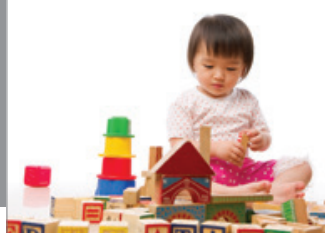

迥
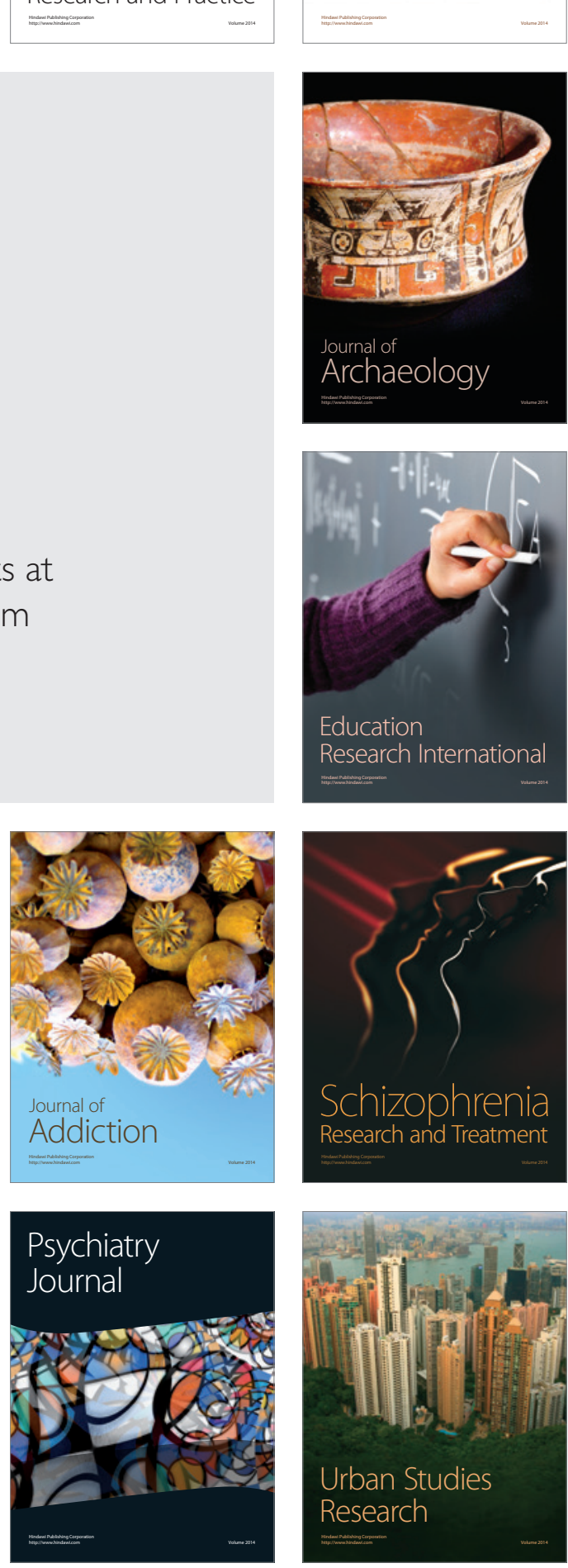